\title{
New Entity of Skull Lesions due to Birth Trauma: Kanat (Wing) Fractures
}

\author{
Ali GEMICI ${ }^{1}$, Aysegul ALKILIC ${ }^{1}$, Pinar GULERYUZ², Selcuk TUNALI ${ }^{3}$, Betul ORHAN KILIC4, Pinar OZISIK \\ ${ }^{1}$ TOBB University of Economics and Technology, School of Medicine, Department of Obstetrics \& Gynaecology, Ankara, Turkey \\ ${ }^{2}$ TOBB University of Economics and Technology, School of Medicine, Department of Radiology, Ankara, Turkey \\ ${ }^{3}$ TOBB University of Economics and Technology, School of Medicine, Department of Anatomy, Ankara, Turkey \\ ${ }^{4}$ TOBB University of Economics and Technology, School of Medicine, Department of Pediatrics, Ankara, Turkey \\ ${ }^{5}$ TOBB University of Economics and Technology, School of Medicine, Department of Neurosurgery, Ankara, Turkey
}

\section{ABSTRACT}

AIM: To discuss a special type of skull lesion detected after delivery. We reviewed our experience on scalp swelling in term neonates to further investigate the relationship between cranial injuries and labor process.

MATERIAL and METHODS: A total of 55 newborns with scalp swellings were assessed with medical records retrospectively between January 2007-July 2017. A radiologist and a pediatric neurosurgeon re-analyzed all skull X-ray images via picture archiving and communication system of the hospital.

RESULTS: A special type of skull fracture, called Kanat (wing) fracture, was detected. The fractures appeared unique, were located in the midline parietal bone, and were difficult to detect by X-ray. Kanat fractures accounted for $12.7 \%$ of the 55 cases ( $n=7$ ). Patients without (group-1) and patients with (group-2) Kanat fractures were compared based on the head circumference of the newborns $(p=0.881)$, fetal birth weight $(p=0.20)$, maternal age $(p=0.04)$, duration of second stage of labor $(p=0.217)$, maternal body mass index $(p=0.278)$, total labor time $(p=0.922)$ and parity $(p=0.375)$. No statistically significant difference between the two groups was determined for the compared parameters.

CONCLUSION: The present study is the first research describing and discussing the possible effects of maternal, fetal and delivery characteristics on Kanat fractures. Designing clinical and experimental researches to enhance awareness and acknowledgement of skull injuries and labor process could improve the clinical outcome of the newborns.

KEYWORDS: Assisted delivery, Birth trauma, Cephalhematoma, Scalp swelling, Skull fracture, Skull X-ray

\section{INTRODUCTION}

A Ithough rare, cranial birth injuries are significant causes of infant morbidity and mortality. As the fetal head is the largest body structure exposed to mechanical forces during labor because of the passage of the newborn through a narrow obstetrical canal, traumatic head injury is a frequently encountered birth-related trauma (32). As a consequence, some changes such as caput succedaneum, subgaleal hemorrhage, scalp bruising, and cephalhematoma are detected in the skull. These changes have a good prognosis but uncommon adverse conditions such as skull fracture, facial paresis, retinal hemorrhage and intracranial hemorrhage can occur (1). In several neurosurgical series, skull fractures represent the most common form of cranial trauma, accounting for approximately $2.9-11.4 \%(1,2,17,26)$. Skull fractures are usually defined as linear, affecting the parietal bones, or depressed, forming the "ping-pong balltype" fracture. Although head computed tomography (CT) 
has been proposed to be conducted in neonates with scalp hematoma to exclude brain injury even in the absence of any neurological signs and symptoms (14), plain X-ray is preferred as a first step intervention as the ionizing radiation dose is low and neonates need not be sedated for the procedure $(5,6,13,16,23)$. However, misreading could possibly occur due to open sutures or vascular grooves. Oh and Yoon were the first authors who hypothesized that the gradual, single directional external pressure on the incompletely ossified skull causes incomplete fractures such as greenstick fractures of the long bones, and they are difficult to visualize using plain X-rays (26). Particularly for medical legal issues, most newborns with scalp lesions still undergo skull X-rays to exclude any skull fracture without further radiological investigation. Therefore, the incidence of the skull fractures may be much higher than those reported to date, indicating that more frequent brain injuries will be accompanied with skull fractures. In our hospital, the evaluation of these plain X-rays led us to the question "Is linear fracture really a fracture in a newborn?" We hypothesize that a special type of skull fracture due to birth trauma with a unique appearance, that is difficult to be detected using X-rays, and may be misdiagnosed as linear fracture could be present.

To better understand the types of skull lesions, presenting features and management approaches, we reviewed our experience with scalp swelling in term neonates to further investigate the relationship between cranial birth injuries and the mode of delivery.

\section{MATERIAL and METHODS}

We performed a retrospective chart review from the medical records including labor and delivery information, and radiological images of neonates presenting with scalp swelling at the Hospital of the TOBB ETU Medical School from January 2007 to July 2017. Mothers using low molecular weight heparin, aspirin or any medication affecting the coagulation system in addition to cases with missing X-rays, and those with multiple gestations were excluded from the study. Fiftyfive newborns, all singleton, delivered at the $37^{\text {th }}$ gestational week, and who presented with scalp swelling were included in the study.

Cases were analyzed on the basis of route of delivery including vaginal, abdominal, assisted vaginal (vacuum or forceps), failed assisted delivery ending with caesarean delivery, labor length, maternal and neonatal information and the radiological images of the newborns. The second stage of labor is defined as the time from complete cervical dilation to fetal expulsion. Maternal and fetal data were obtained from maternal and pediatric files. Cephalhematoma, subgaleal hematoma/caput succedaneum, and skull lesions were diagnosed clinically and by using the two views of skull X-ray (PA and lateral). Although subgaleal hematomas are also known to have subperiosteal components (cephalhematomas), scalp swellings were divided in two groups. Cephalhematoma (Figure 1) is defined as a swelling that does not cross the suture lines, and subgaleal hematoma (Figure 2A, B) is defined as a swelling that crosses the suture lines.
All skull X-rays were performed on the first or the second day of life. A radiologist and a pediatric neurosurgeon re-analyzed all X-ray images using the picture archiving and communication system (PACS) of the hospital. One-sided blindness was achieved for interpretation. Both specialists performed their interpretation independently, without knowing the previous diagnosis and the other specialist's diagnosis. Afterwards, the diagnostic differences including previous-current diagnostic difference and current diagnostic difference of each were noted, both specialists performed the re-interpretation together, and consensus was achieved for contradicting diagnoses. In case of disagreement, these cases were accepted as normal.

The follow-up clinical data of the neonates were assessed from their routine outpatient clinic files of the pediatric department for six months.

Descriptive statistics were used (frequency, mean or median and range) for continuous data. The statistical analysis was performed by IBM statistics SPSS 20.0 software. After performing normalisation tests on parametric data, Student $t$-test and Mann-Whitney U-test were used for data with normal and non-normal distributions, respectively. $p$ values $<0.01$ were considered statistically significant. In determining the difference between two variables by time, namely, the duration of second stage of labor time, and total labor, a $p$ value of $<0.025$ was considered statistically significant, based on Bonferroni correction.

\section{RESULTS}

We evaluated 55 cases, accounting for $0.5 \%$ of all deliveries in a 10- year period. We detected 21 and 34 cases of subgaleal hematoma and cephalhematoma, respectively. The mean maternal age was $30.44 \pm 3.30$ years (SD). The mean estimated gestational age was 39 weeks and 3 days (min: 37 weeks and 6 days, max: 40 weeks and 2 days). The mean body mass index (BMI) of mothers was $28.13 \pm 6.46 \mathrm{~kg} / \mathrm{m}^{2}$. The mean birth weight of the newborns was $3375.54 \pm 284.28$ g. Forty-five women were nulliparous, accounting for $81.1 \%$ of total cases wherein one newborn was delivered by caesarean section, and the remaining newborns were delivered vaginally.

Nine newborns (16.3\%) had assisted delivery: vacuum extraction- ( 5 cases), kiwi extraction ( 3 cases), and, outlet forceps (1 case). Of the newborns, six had subgaleal hematomas, with a predisposition for bigger scalp swelling, and three had cephalhematomas. The protracted second stage of labor ( $>2$ hours) accounted for $3.6 \%$ of newborns ( $n=2)$, and one newborn had accompanying subgaleal hematoma, and the other newborn had cephalhematoma, and none needed assisted delivery.

The evaluation of previous reports of skull X-rays in our series, showed that two newborns were reported to have linear fracture and one newborn was reported to have suspicious linear fracture. The other 52 skull $X$-rays were reported to be normal. All skull X-rays were evaluated as mentioned above. We did not find any ping-pong ball fracture, or a regular traumatic linear fracture, but a special type of fracture was diagnosed in seven newborns. 
This special type of skull fracture is located in the medial border of the parietal bone, seen only on lateral X-rays, has very short length (in contrast to regular traumatic linear fractures), is nondisplaced, and some of them follow the suture notch similar to a tear. The appearance of the fracture/tear also changes

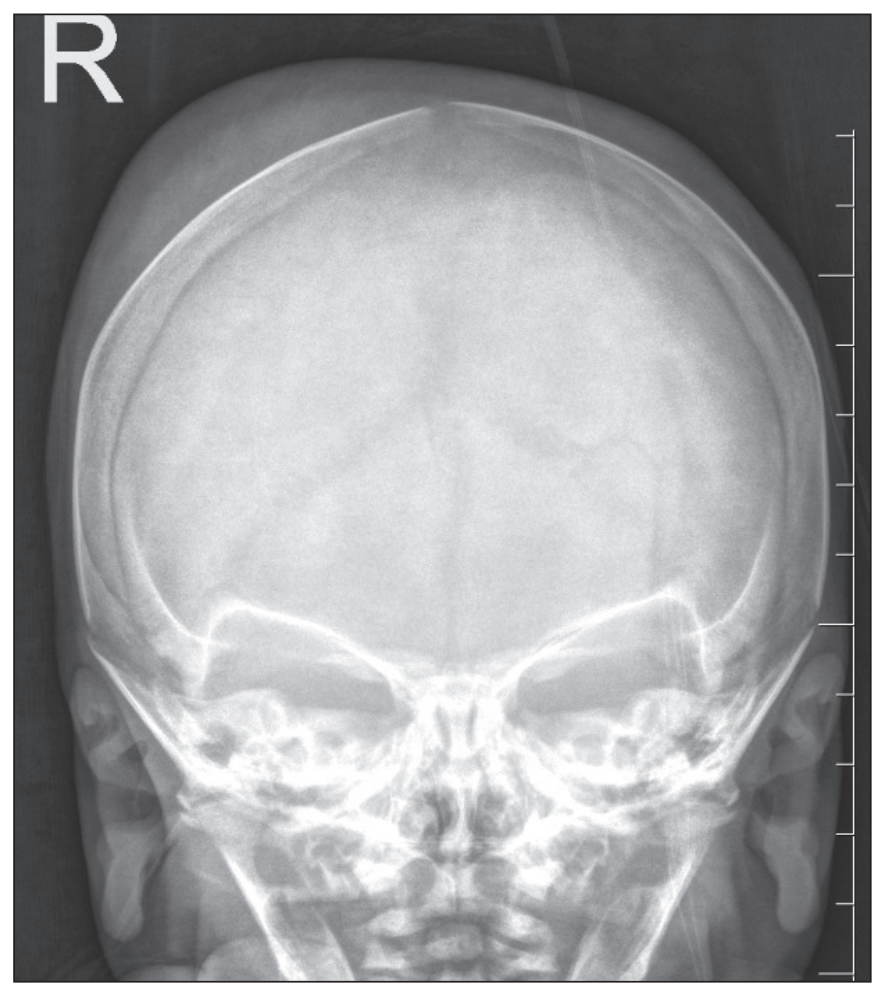

Figure 1: PA skull radiograph showing right parietal cephalhematoma that is not crossing the sagittal suture. based on the mineralisation of the parietal bone. The fracture can appear similar to a linear fracture in a more mineralised (ossified) bone; however, it has a short length at $1-2 \mathrm{~mm}$, and is located on the medial (midline) aspect of the parietal bone (Figure 3A, B: The skull X-rays of this case were initially reported as normal by the radiologist). Regular linear fractures caused by trauma are longer, and can cross the midline or suture lines.

We presumed that the appearance of fracture/tear may change based on the developmental variations of the parietal bone. Figure 4A shows the normal suture appearance of the posterior parietal bone that is less demineralised (underossification) and also with right parietal subperiosteal hematoma. The depth of the notch of the sutures can be easily seen (arrow). However another plain X-ray (Figure 4B) shows that the tear/fracture from the notch is longer, more separated, and has irregular edges. This is the second type of special bone lesion seen due to birth trauma. Figure $5 \mathrm{~A}-\mathrm{C}$ shows another example of these fractures.

Five cases appeared to be a tear, and two other cases appeared like a fracture, which is why we decided to use a new nomination to describe parietal, midline tear/fracture lesions on the skull X-ray as "Kanat fractures". Kanat is a Turkish word, a synonym of "wing" in English. We decided to use the term because suture configuration appeared to be like little wings, and the location of fractures was related to the sagittal suture. Kanat (wing) fracture accounted for $12.7 \%$ of 55 cases $(n=7)$. Four and three newborns had cephalhematomas and subgaleal hematomas, respectively. The skull X-rays of four newborns were first reported to be normal; two newborns were reported to have a linear fracture, and one newborn was reported to have a suspicious linear fracture. The misdiagnosis rate was $57 \%$. Transfontanel ultrasound was performed in
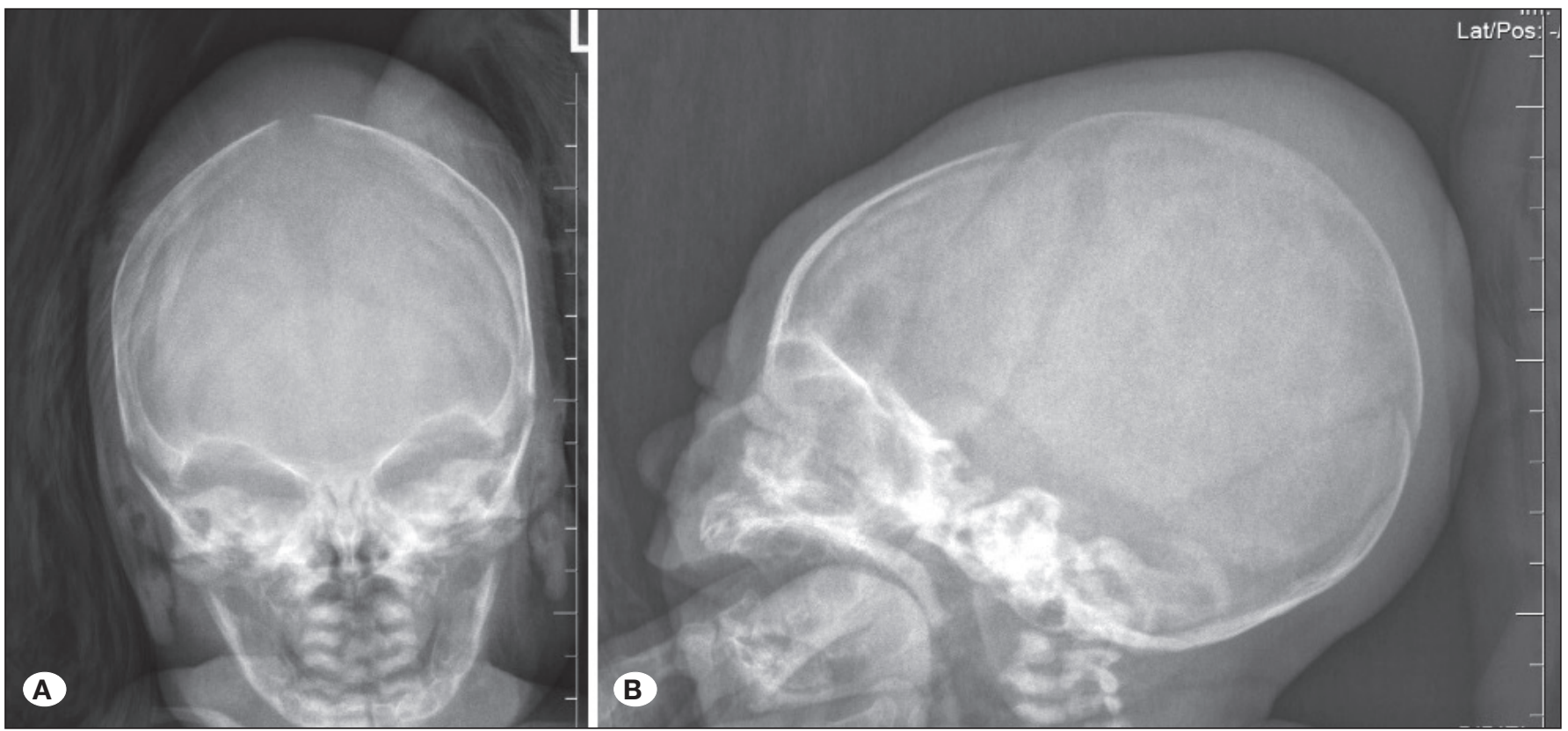

Figure 2: Skull radiographs of a 39-week and 5 day gestational age boy weighing $3725 \mathrm{~g}$, with a $34 \mathrm{~cm}$ skull circumference, and vacuumassisted labor. PA (A) and lateral (B) skull X-ray showing bilateral frontoparietal subgaleal hematoma. 
two cases (in one fracture and one suspicious fracture cases) reported to be normal. Transfontanel ultrasonography was not performed in the remaining 5 cases because skull X-rays were reported to be normal, and suspicious fracture in four cases and one case, respectively.

The main maternal and obstetrical characteristics of the study group in these patients are presented in Table I. Kanat fracture was detected in one newborn with assisted delivery (kiwi extraction). In contrast, a protracted second stage was not detected in any case of Kanat fracture.

In the follow-up period, calcified subperiosteal haematoma was detected in 2 of 55 newborns. None of the newborns presented to our clinics with any neurologic complaint or symptom.
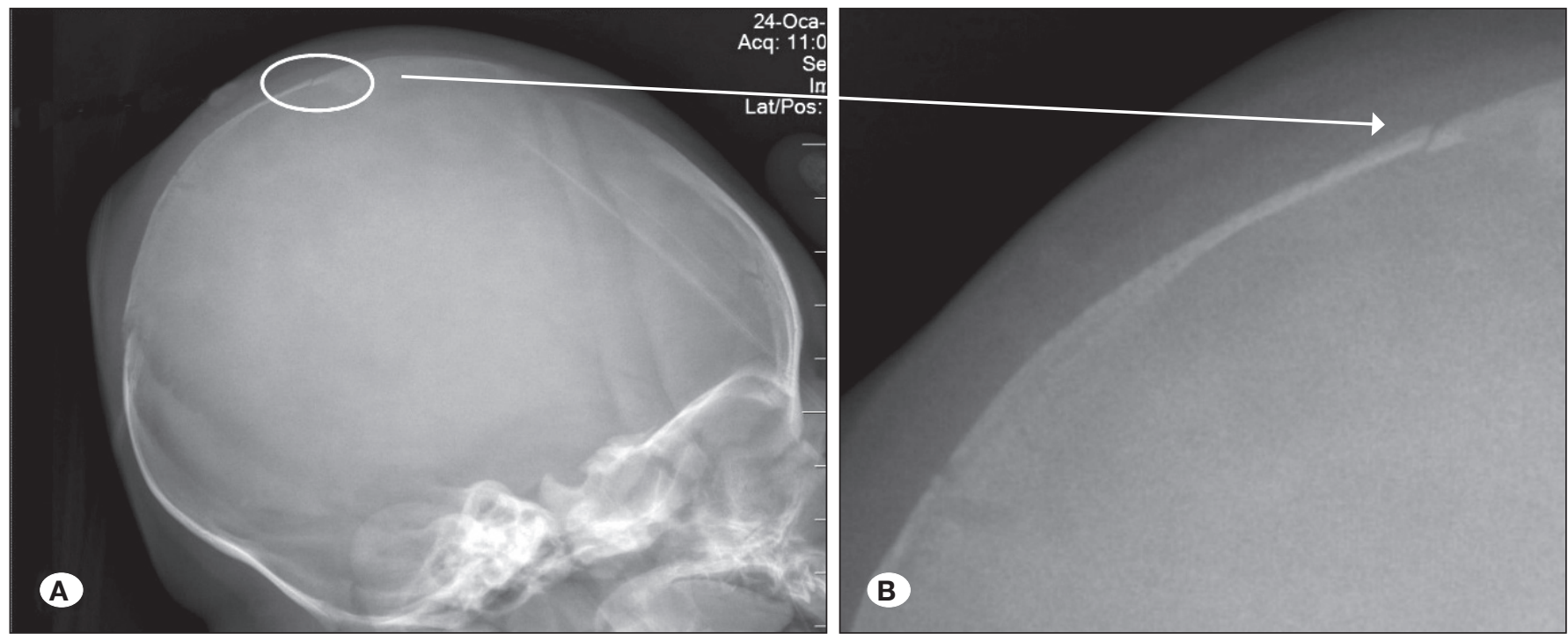

Figure 3: Skull radiographs of a 40-week and 1 day gestational age girl weighing $3580 \mathrm{~g}$, with a $34 \mathrm{~cm}$ skull circumference, and spontaneous labor. A) Lateral skull X-ray of the newborn with a right parietal cephalhematoma. B) Magnification of the skull fracture on the central part of parietal bone at midline.
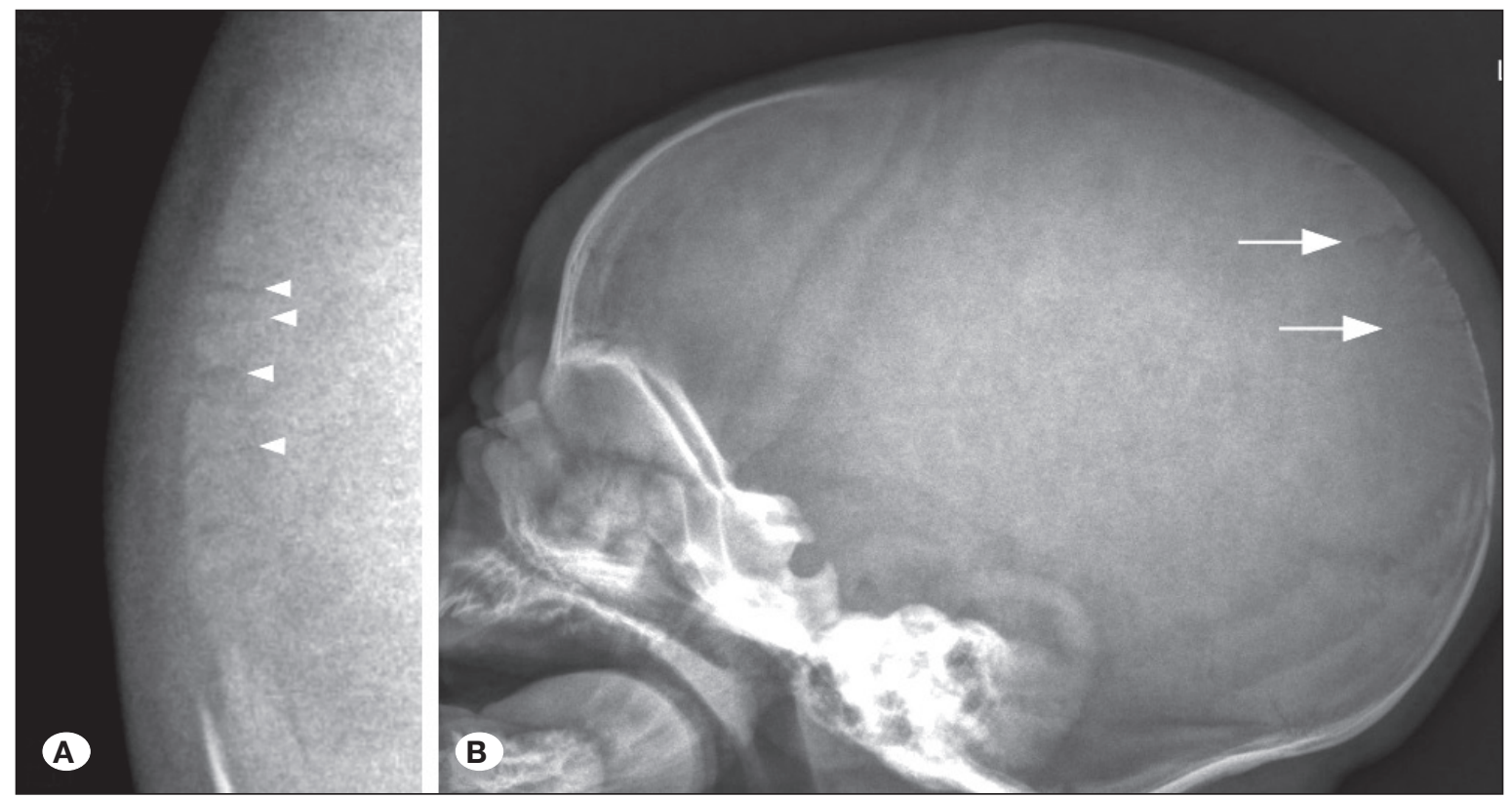

Figure 4: A) Lateral skull radiograph of a 39-week gestational age girl weighing $3060 \mathrm{~g}$, with $34 \mathrm{~cm}$ skull circumference, spontaneous labor, and right parietal cephalhematoma. It demonstrates the normal radiological appearance of the sagittal suture on the posterior parietal bone with magnification $(\times 3)$. Arrowheads show the depth of the suture notches. B) Lateral skull radiograph of a $37-$ week and 1 day gestational age boy weighing $3105 \mathrm{~g}$, with $32.6 \mathrm{~cm}$ skull circumference, spontaneous labor, and left parietal cephalhematoma. It shows Kanat fractures/tears on the posterior parietal area at midline, following sutural notches (arrows), and the length of the Kanat fractures are $>1 \mathrm{~cm}$. 


\section{Statistical Analysis}

Tables II and III show the statistical analysis of the study. The parameters in Table II and III were analysed with Student's ttest and Mann-Whitney $U$ test. No significant difference was found between the groups 1 (cases without Kanat fracture) and 2 (cases with Kanat fracture) based on the head circumference of the newborns $(p=0.881)$, and fetal birth weight $(p=0.20)$. Other parameters such as maternal age $(p=0.04)$, duration of the second stage of labor $(p=0.217)$, maternal BMI $(p=0.278)$, total labor duration $(p=0.922)$, and parity $(p=0.375)$, were also similar in the two groups. Consequently, the studied variables were not detected to induce Kanat fracture in the study population.

\section{DISCUSSION}

Although the overall incidence of birth injuries has continued to decrease due to advances in obstetric techniques/neonatal care, fetal head injuries and maternal complications can still arise after labor.

The fetal head is characterized by plasticity, and considerable molding of the cranial vault can occur during delivery due to compressive stress on all sides. However, most of the force is applied to the occipitofrontal direction that frequently causes both parietal bones to be displaced posteriorly and superiorly, with concomitant rotation of the occipital and temporal bones as well as suture overlap. The fetal head may be tightly wedged in the birth canal when arrest of descent occurs as the cervix is fully dilated and the uterus undergoes vigorous contractions. During this process the skull may be compressed by the maternal $5^{\text {th }}$ lumbar vertebrae, sacral promontory, symphysis pubis, ischial spines, or asymmetric or contracted pelvis, and also when forceps or vacuum is applied to the skull $(10,15)$. This molding usually disappears within 2-3 days. Sometimes the sutures of the newborns are seen to transiently widen, perhaps because of postpartum cerebral swelling.

Significant changes in the geometry of the fetal head that occur during vaginal deliveries, with compression in the occipitofrontal dimension and overlap of frontal and parietal bones may cause direct brain damage. The most common clinical presentations of head injury due to birth were scalp swelling (43-56.6\% of cases) and seizures (19\% of cases) $(2,4,11,30)$. Other presenting signs included apnea (14\%), focal neurologic deficits $(14 \%)$, bradycardia $(9.5 \%)$, and respiratory distress $(4.8 \%)(11,30)$. Hughes et al. showed that the incidence of skull fracture was $2.9 \%$ (17). In another series by Bhat et al., bone injuries were observed to occur in 1/1000 live births, and only $11.4 \%$ of bone injuries were skull fractures (2). However, the incidence is increasing to up to $33 \%$ as the most common cranial lesion among craniocerebral birth injuries based on patients who presented to a neurosurgical clinic $(25,28)$. Although head CT is superior to plain X-rays in detecting skull fractures or intracranial pathologies (7), it exposes neonates to high doses of ionizing radiation and neonates need to be sedated for the procedure (27). That is
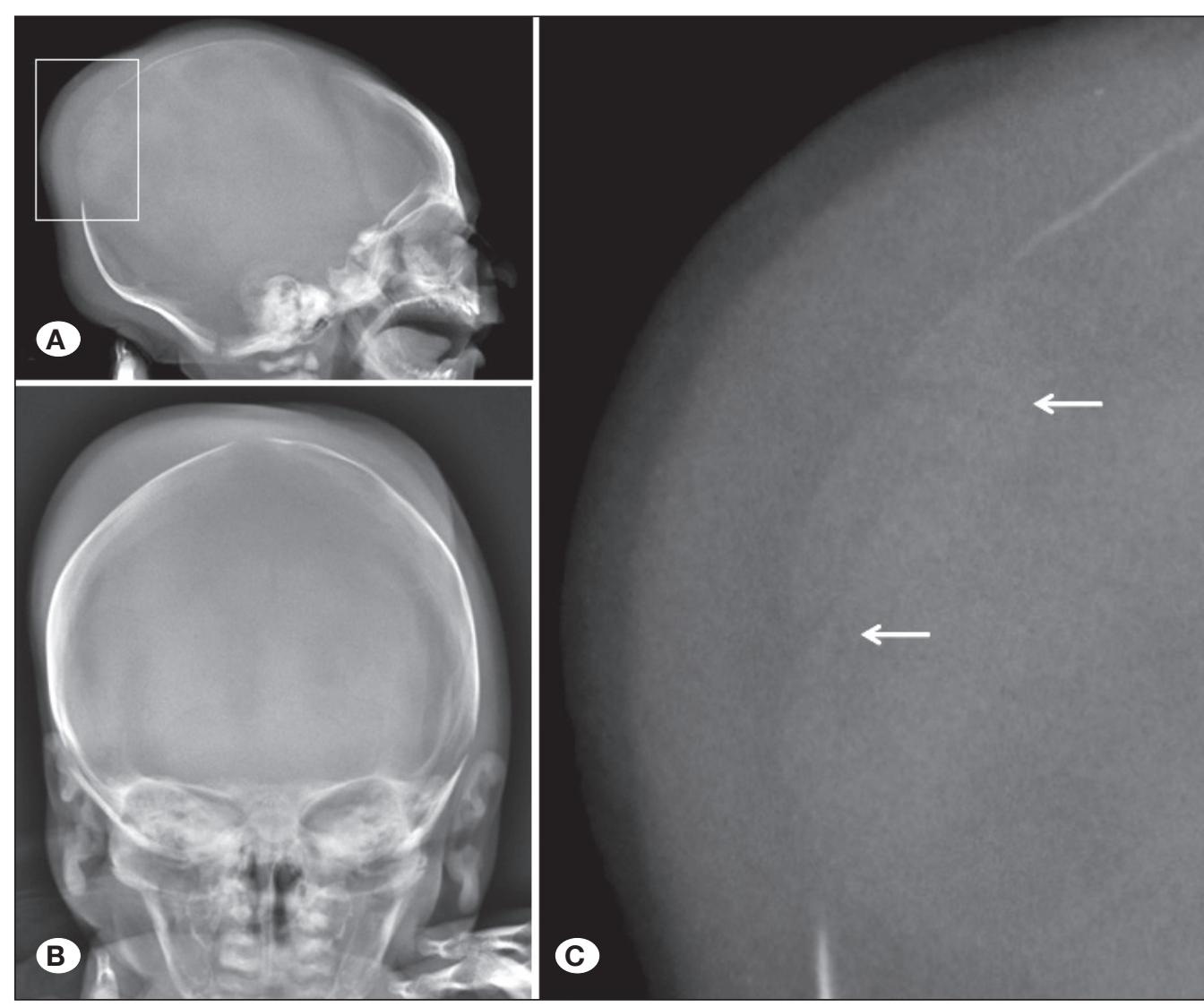

Figure 5: A) Lateral skull radiograph of a 39-week gestational age boy weighing $3550 \mathrm{~g}$, with a $35.5 \mathrm{~cm}$ skull circumference, spontaneous labor, and parietal subgaleal/ cephalhematoma. B) PA skull radiograph of the newborn showing bilateral parietal subgaleal hematoma $(R>L)$. C) Posterior part of the lateral skull radiograph of the same newborn. It is showing the Kanat fractures on the posterior parietal bone with magnification (x2.5). Inferior arrow showing upward directed, longer tear of the bone. 
why plain film radiography remains the most cost effective method in evaluating skull fractures and can easily differentiate major sutures and common vascular grooves from fractures. Misreading of plain X-rays may be possible due to open sutures, presence of numerous synchondroses and unusual accessory sutures or vascular grooves (29). In addition, hair and scalp often cause confusing shadows on skull radiographs such as skin folds, hair braids, matted hair, and folded earlobe. Vascular markings are due to dural venous sinuses, diploic or emissary veins, and meningeal vessels which are usually not absent in the newborn skull. Vascular markings become more apparent as the bony calvaria develop into an inner table, diploic space, and outer table. Dural venous sinus grooves may be initially identified at approximately 3 years of age.

Information on birth injuries and skull X-rays of these injuries were mainly discussed in case reports in several languages $(18,22,33,34)$. Skull injuries caused by vaginal deliveries were discussed mainly for intracranial injuries and published mostly in obstetric, radiology and pediatric journals $(12,19,20,31)$. Other pathologies such as linear fractures, growing skull fractures, leptomeningeal cysts and depression fractures were also discussed in the case series and not only birth injuries but also accidental and non-accidental childhood head injuries were included in the series and discussed $(3,19,24)$. As a result, the incidence of skull injuries resulting from labor is still unknown.

We present our data from a series of infants diagnosed with skull swelling and managed at our institutions. The diagnostic significance of the labor process, and the radiological appearance of pathologic cases have been emphasized. This is the first study combining obstetrical, maternal and newborn clinical data in mis-defined skull lesions (incomplete skull fracture, greenstick fracture, and linear fracture) in the literature due to birth trauma. Our preliminary results showed that head circumference, fetal birth weight, maternal BMI, parity, total labor duration, and duration of second stage of labor did not induce effects on defined skull injuries. None of these patients presented with any other neurological symptoms other than scalp swelling. In addition, no neurological complaints were recorded in the paediatric clinic during the routine check-ups in 6 month period after delivery.

We presume that Kanat (wing) fracture may be the consequence of the pressure applied to the fetal head. In this study, all the scalp swellings of the 55 newborns were located on the parietal and parietooccipital regions. Therefore we hypothesize that scalp swellings are located in this area because the parietal bone is the axis of the pressure zone of the cranium during labor; hence, the abnormal appearance of the bones should not be directly considered as a variation. With development, the ossification in the parietal bone uniformly radiates, but the parietal bone has a lot of variations associated with ossification, including parietal incisura, parietal irregularity and fissuring in X-ray (21) (Figure 6A, B). However, the information in the textbooks did not include the clinical characteristics of newborns, or why these X-rays were performed. It is also interesting that the mentioned variations were not seen on other skull bones. 
Table II: Comparison Table of the Groups with the Parameters of Maternal Age, Fetal Birth Weight and Second Stage of Labor Time

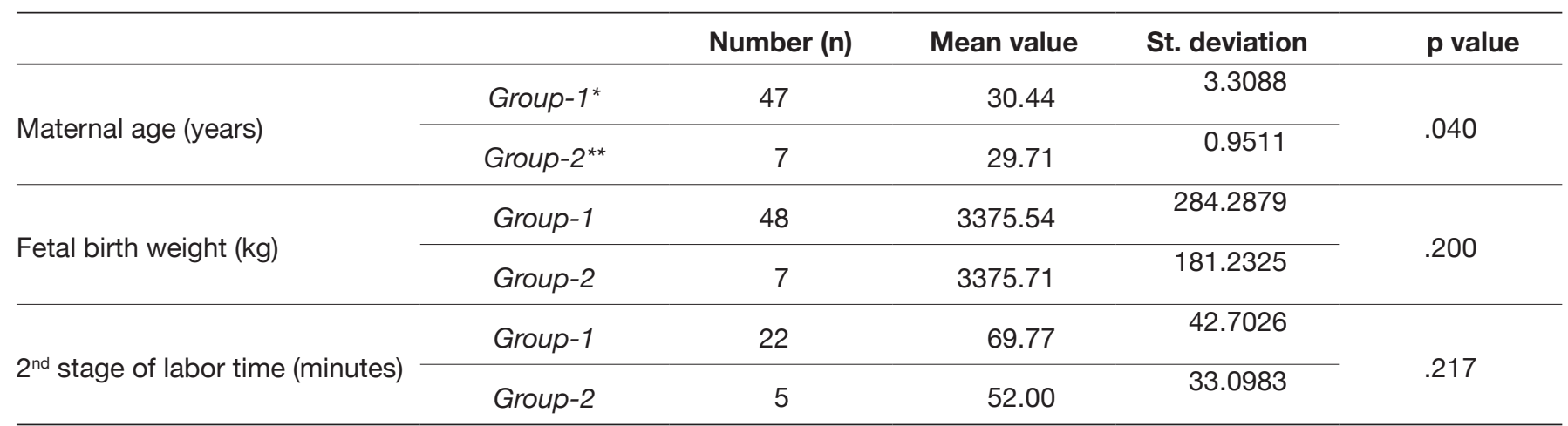

* group-1: newborns without Kanat fracture ${ }^{* *}$ group-2: newborns with Kanat fracture.

Table III: Comparison of the Groups with the Parameters of Fetal Head Circumference, Maternal BMI, Total Labor Time, and Multiparity

\begin{tabular}{lcccc}
\hline & & Number $(\mathbf{n})$ & Mean rank & p value \\
\hline \multirow{2}{*}{ Fetal head circumference $(\mathrm{cm})$} & Group-1* $^{*}$ & 39 & 23.64 & .881 \\
\cline { 2 - 4 } Maternal BMI $\left(\mathrm{kg} / \mathrm{m}^{2}\right)$ & Group-2 $^{* *}$ & 7 & 22.71 & 25.59 \\
\hline \multirow{2}{*}{ Total labor time (minutes) } & Group-1 & 45 & 32.36 \\
\hline & Group-2 & 7 & 24.90 \\
\cline { 2 - 4 } Multiparity & Group-1 & 42 & 25.57 \\
\hline
\end{tabular}

*group-1: newborns without Kanat fracture, **group-2: newborns with Kanat fracture, BMI: Body mass index.
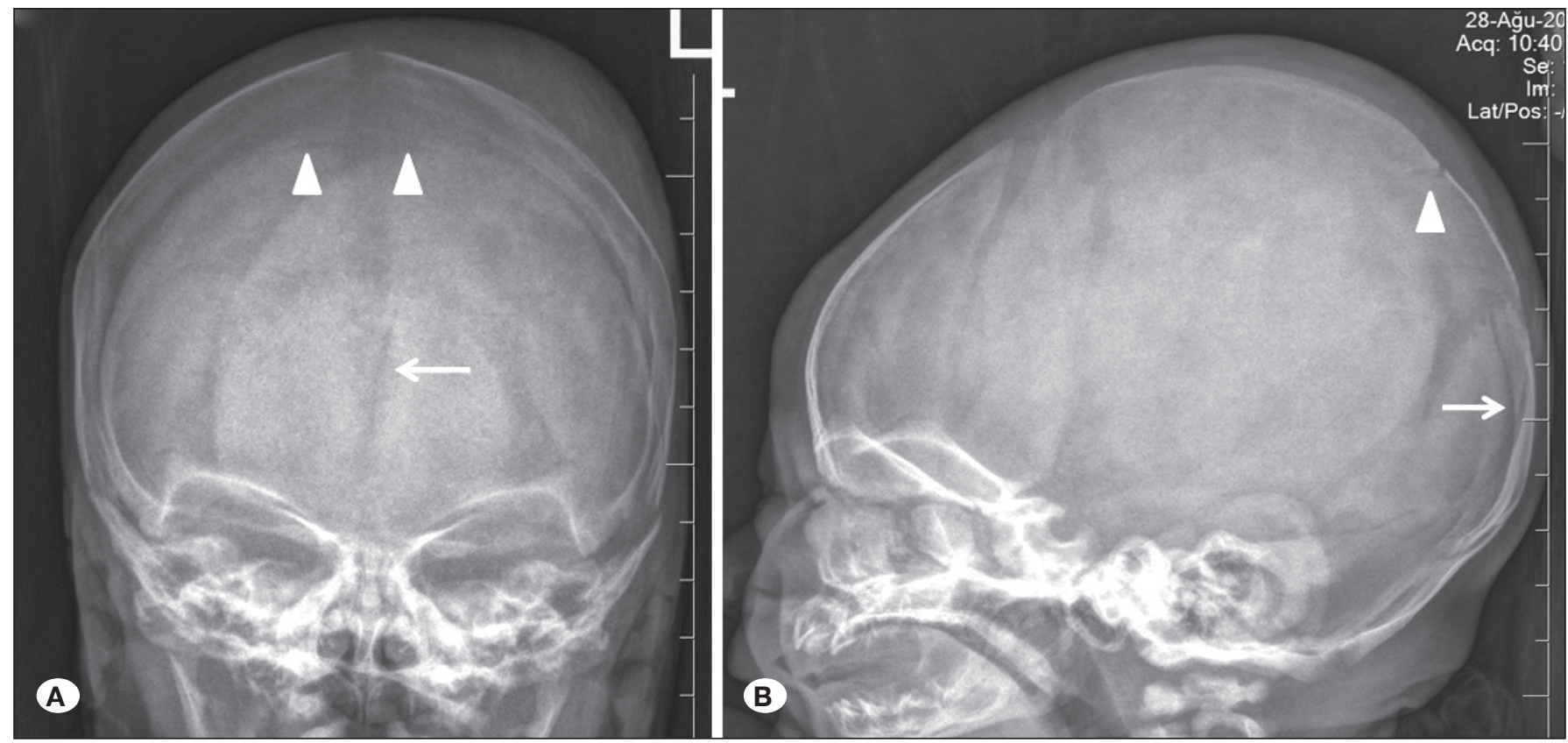

Figure 6: Skull radiographs of a 40-week and 1 day gestational age boy weighing $3710 \mathrm{~g}$, with a $34 \mathrm{~cm}$ skull circumference, and spontaneous labor. PA (A) and lateral (B) skull X-ray showing left parietal cephalhematoma. White arrows show occipital accessory suture, and arrowheads show parietal fissuring located on bilateral parietal bones. 
The kind of forces involved in Kanat (wing) fractures is unclear. When rotational or pulling forces are present, we hypothesize that the bone is irregularly tearing from the suture notch similar to a sheet of paper. We speculated that even scalp hematoma may be developed by these forces by separating the bone from the periosteum, most tightly attached to the bone at the suture lines. The pathophysiological mechanism of cephal hematoma development is speculated to be related to tearing of subperiosteal blood vessels by sudden compression of the skull or shearing forces between the skull and periosteum, causing periosteum stripping from the underlying skull bone (8). Hematoma advancing toward the bone margins creates a force that pulls the bone upwards; however, opposing forces originating from the bone that adheres tightly to the dura inferiorly in the suture line resist this separation. Consequently, the pliable bone may tear where we thought was the thinnest part. This tear is a full tear rather than an incomplete (greenstick) fracture.

Although we did not detect any neurologic pathology in our study population, this kind of fracture may be clinically important because venous sinus injury may occur after dura mater injury; hence the fracture occurs in the midline. Growing skull fractures, and leptomeningeal cysts related to birth trauma were only occasionally reported, but these fractures may also cause these pathologies and be inadvertently misdiagnosed as suture disruptions.

In another study comparing 101 newborn scalp swellings with plain X-ray and three-dimensional (3D) cranial CT, Cho et al. stated that the incidence of skull lesions described as greenstick fractures was higher than that of the general population (9). In contrast, 3D CT is speculated to give approximately twice as high radiation as 2D CT. Consequently, we believe that rather than extended usage of 3D CT, 3D CT may better elaborate scalp swellings in newborns with neurological findings. Moreover, they found three depressed and four linear fractures among 101 patients but did not mention any intracranial pathology. Recent neuroradiological studies indicate that intracranial hemorrhage, even in asymptomatic infants, is not rare and that small intracranial hemorrhages in both spontaneous and assisted vaginal births can spontaneously resolve $(11,30)$. Because these conditions are newly described entities, consensus on this issue has not been established yet. Many questions on diagnostic and management approaches are waiting to be answered; namely, performing two views rather than the lateral X-ray for the initial diagnosis, using CT as a diagnostic tool, and whether all newborns should undergo transfontanel ultrasonography. Besides, compared with X-ray and transfontanel ultrasound, no data demonstrated the additive effect of CT scan in the clinical management or treatment of those cases with normal neurological examination.

The labor process may apparently cause more injury/lesions in the skull than our knowledge considering the current literature. Hence, the awareness of these lesions is very low among related medical doctors such as radiologists, neurosurgeons, pediatricians, and the misdiagnosis rate is high. An increasing number of publications on skull lesions and birth is needed to provide answers to clinical questions. Thus, new radiological modalities can be developed for accurately detecting skull injuries, the possibility of dura mater and intracranial injuries can be estimated, and clinical follow-up of the newborns can be defined.

\section{- CONCLUSION}

Skull lesions detected after delivery including fractures/tears are higher than our estimation. Although X-ray assessment is insufficient in diagnosing all of these lesions, CT scan can be performed based on the neurological status. In addition, it is better to design prospective large-scale experimental studies comparing and analyzing Kanat (wing) fracture clinics and the possible radiological assessment of those cases.

\section{- REFERENCES}

1. Alexander JM, Leveno KJ, Hauth J, Landon MB, Thom E, Spong CY, Varner MW, Moawad AH, Caritis SN, Harper M, Wapner RJ, Sorokin Y, Miodovnik M, O'Sullivan MJ, Sibai BM, Langer O, Gabbe SG; National Institute of Child Health and Human Development Maternal-Fetal Medicine Units Network. Fetal injury associated with cesarean delivery. Obstet Gynecol 108: 885-890, 2006

2. Bhat BV, Kumar A, Oumachigui A: Bone injuries during delivery. Indian J Pediatr 61: 401-405, 1994

3. Bode-Jänisch S, Bültmann E, Hartmann H, Schroeder G, Zajaczek JE, Debertin AS: Serious head injury in young children: Birth trauma versus non-accidental head injury. Forensic Sci Int 10: 34-38, 2012

4. Bowman R, Tomita T: Birth head trauma. In: Youmans JR (ed), Neurological Surgery. Philadelphia: WB Saunders, 2009: 3481-3487

5. Brenner D, Elliston C, Hall E, Berdon W: Estimated risks of radiation-induced fatal cancer from pediatric CT. AJR Am J Roentgenol 176: 289-296, 2001

6. Brenner DJ, Hall EJ: Computed tomography-an increasing source of radiation exposure. N Engl J Med 357: 2277-2284, 2007

7. Browning JG, Reed MJ, Wilkinson AG, Beattie T: Imaging infants with head injury: Effect of a change in policy. Emerg Med J 22: 33-36, 2005

8. Bruce DA, Schut L, Sutton LN: Cephalhematoma and subgaleal hematoma. In: Wilkins RH, Renganchary SS (eds), Neurosurgery. 2nd ed. New York: McGraw-Hill, 1985:16221623

9. Cho SM, Kim HG, Yoon SH, Chang KH, Park MS, Park YH, Choi MS: Reappraisal of neonatal greenstick skull fractures caused by birth injuries: Comparison of 3-dimensional reconstructed computed tomography and simple skull radiographs. World Neurosurg 109:e305-e312, 2018

10. Cunningham FG, Leveno KJ, Bloom SL, Hauth JC, Gilstrap $\mathrm{JC}$, Wenstrom KD: Diseases and injuries of the fetus and newborn: Williams obstetrics. 22 ${ }^{\text {nd }}$ ed. Boston: McGraw-Hill, 2005 
11. Ekéus $C$, Högberg U, Norman M: Vacuum assisted birth and risk for cerebral complications in term newborn infants: A population-based cohort study. BMC Pregnancy Childbirth 14: 36, 2014

12. Ghidini A, Stewart D, Pezzullo JC, Locatelli A: Neonatal complications in vacuum-assisted vaginal delivery: Are they associated with number of pulls, cup detachments, and duration of vacuum application? Arch Gynecol Obstet 295: 67-73, 2017

13. Gogos KA, Yakoumakis EN, Tsalafoutas IA, Makri TK: Radiation dose considerations in common pediatric X-ray examinations. Pediatr Radiol 33: 236-240, 2003

14. Greenes DS, Schutzman SA: Clinical indicators of intracranial injury in head-injured infants. Pediatrics 104:861-867, 1999

15. Heise RH, Srivatsa PJ, Karsell PR: Spontaneous intrauterine linear skull fracture: A rare complication of spontaneous vaginal delivery. Obstet Gynecol 87: 851-854, 1996

16. Huda W, Atherton JV, Ware DE, Cumming WA: An approach for the estimation of effective radiation dose at CT in pediatric patients. Radiology 203: 417-422, 1997

17. Hughes CA, Harley EH, Milmoe G, Bala R, Martorella A: Birth trauma in the head and neck. Arch Otolaryngol Head Neck Surg 125: 193-199, 1999

18. Johannesen KM, Stantchev H: Neonatal skull fracture. Ugeskr Laeger 176(7A): V08130515, 2014

19. Kilani RA, Wetmore J: Neonatal subgaleal hematoma: Presentation and outcome-radiological findings and factors associated with mortality. Am J Perinatol 23: 41-48, 2006

20. King SJ, Boothroyd AE: Cranial trauma following birth in term infants. Br J Radiol 71: 233-238, 1998

21. Kirks DR, Griscom NT: Practical pediatric imaging. In: Diagnostic Radiology of Infants and Children. Chapter 2: Skull and Brain. Lippincott Williams \&Wilkins, 1998: 65-200

22. Machado A, Rocha G, Silva Al, Alegrete N, Guimarães H: Bone fractures in a neonatal intensive care unit. Acta Med Port 28: 204-208, 2015
23. Mettler FA Jr, Wiest PW, Locken JA, Kelsey CA: CT scanning: Patterns of use and dose. J Radiol Prot 20: 353-359, 2000

24. Miranda P, Vila M, Alvarez-Garijo JA, Perez-Nunez A: Birth trauma and development of growing fracture after coronal suture disruption. Childs Nerv Syst 23: 355-358, 2007

25. Nachtergaele P, Van Calenbergh F, Lagae L: Craniocerebral birth injuries in term newborn infants: A retrospective series. Childs Nerv Syst 33: 1927-1935, 2017

26. Oh $\mathrm{CK}$, Yoon SH: The significance of incomplete skull fracture in the birth injury. Med Hypotheses 74: 898-900, 2010

27. Olsen EA, Brambrink AM: Anesthesia for the young child undergoing ambulatory procedures: Current concerns regarding harm to the developing brain. Curr Opin Anaesthesiol 26: 677-684, 2013

28. Pollina J, Dias MS, Li V, Kachurek D, Arbesman M: Cranial birth injuries in term newborn infants. Pediatr Neurosurg 35: 113-119, 2001

29. Quayle KS, Jaffe DM, Kuppermann N, Kaufman BA, Lee BC, Park TS, McAlister WH: Diagnostic testing for acute head injury in children: When are head computed tomography and skull radiographs indicated? Pediatrics 99: E11, 1997

30. Reichard R: Birth injury of the cranium and central nervous system. Brain Pathol 18: 565-570, 2008

31. Simonson C, Barlow P, Dehennin N, Sphel M, Toppet V, Murillo D, Rozenberg S: Neonatal complications of vacuum-assisted delivery. Obstet Gynecol 109: 626-633, 2007

32. Tekes A, Pinto PS, Huisman TA: Birth-related injury to the head and cervical spine in neonates. Magn Reson Imaging Clin N Am 19: 777-790, 2011

33. Villarejo F, Belinchón JM, Carceller F, Gómez-Sierra A, Pascual A, Cordobés F, Pérez-Díaz C, Rivero B: Cranial lesions due to forceps delivery. Neurocirugia (Astur) 20: 262-264, 2009

34. Zakanj Z: Skull fracture and cephalhematoma in a newborn-a case report. Lijec Vjesn 136: 335-338, 2014 